Vol. 28, No. 01, pp.25-40/Junio 2015

\title{
LA BIOPRECIPITACIÓN DE CARBONATO DE CALCIO POR LA BIOTA NATIVA COMO UN MÉTODO DE RESTAURACIÓN.
}

\section{THE BIOPRECIPITATION OF CALCIUM CARBONATE BY NATIVE MICROBIAL POPULATION AS A RESTORATION METHOD. \\ Leandro Alberto Páramo Aguilera ${ }^{1}$, José Alberto Narváez Zapata ${ }^{2}$ y Benjamín Otto Ortega Morales ${ }^{3}$.}

\author{
${ }^{1}$ Programa de Investigación y Estudios Nacionales y Servicios Ambientales (PIENSA), \\ Universidad Nacional de Ingeniería, UNI. Managua, Nicaragua. \\ E-mail: 1paramo99@yahoo.com
}

${ }^{2}$ Instituto Politécnico Nacional (IPN), Centro de Biotecnología Genómica (CBG), Blvd del Maestro esq Elías Piña Col Narciso Mendoza C.P 88710. Cd Reynosa, Tam, Mex, A.P Nº 152. E-mail: jnarvaez@ipn.mx

${ }^{3}$ Laboratorio de Microbiología de la Universidad Autónoma de Campeche, UAC, Campeche, México. e-mail: benottto@yahoo.com.mx

(recibido/received: 28-Enero-2015; aceptado/accepted: 10-Junio-2015)

\section{RESUMEN}

Partiendo de 30 aislados bacterianos de diferentes tipos (fundamentalmente Bacillus), previamente aislados e identificados por métodos microbiológicos y moleculares, provenientes de biopelículas epilíticas aisladas del Castillo de Chapultepec de la ciudad de México, DF. Se realizaron diferentes metodologías como comprobación de capacidad para formar biopelículas y su cuantificación, prueba de ureasa y la producción de cristales de carbonato de calcio en placa Petry con Luria Bertani enriquecido con carbonato de calcio al $0.2 \%$. Los cristales fueron enviados a difracción de rayos X y Microscopia Electrónica de Barrido.

Los resultados muestran que en alguna medida todos los microorganismos probados participan en el proceso de formación de biopelículas y un total de 12 aislados destacaron como los mejores formadores de biopelículas, sobresaliendo las cepas IS16 y IIIS10 (Bacillus subtilis), IIS15a (Bacillus cereus) por ser las que mayores UFC/mL presentaron en la biopelícula. Todos los buenos formadores de biopelículas resultan también adecuados en cuanto a bioprecipitación de carbonatos, destacando las cepas IIIS4 (Bacillus megaterium), IS5 (Bacillus subtilis), IIIS9b (Bacillus subtilis), 21 (Pantoea agglomerans) y la IIIS5 (Bacillus simplex). Poco o nada se sabe hasta el momento de la participación de Pantoea agglomerans en procesos de biorrestauración mediante bioprecipitación de cristales de carbonato de calcio y debido a que se obtuvo buena respuesta a la prueba de ureasa y los cristales obtenidos fueron mayormente Calcita (99\%), este trabajo muestra la factibilidad de usar la biota nativa para su activación y así lograr la restauración de los monumentos biodeteriorados.

Palabras claves: Roca caliza; bioprecipitación bacteriana; Calcita; Aragonita; Biodeterioro y biorrestauración.

\begin{abstract}
A selection of 30 previously isolated bacteria of different types were taken, mainly Bacillus, which had been previously identified by microbiological and molecular methods to be epilithic biofilms from Chapultepec's Castle in Mexico City, DF. Different methodologies were practiced to determine which of them were forming biofilms and their quantification, the ureasa test and the production of crystals of
\end{abstract}

Nexo Revista Científica Vol. 28, No. 01, pp. 25-40/Junio 2015 
calcium carbonate in Petry plate with Luria Bertani enriched with calcium carbonate to $0.2 \%$. The crystals obtained were submitted to diffraction of X-rays and Electronic Microscopy of Sweep.

The results show that all microorganisms tested were involved in the process of biofilm formation, and only 12 isolates, including the IS16 (Bacillus subtilis); IIS15a (Bacillus cereus) and IIIS10 (Bacillus subtilis) strains, were the best biofilm formers with high UFC / $\mathrm{mL}$, good in terms of bioprecipitation of carbonates. Particularly, the strains IIIS4 (Bacillus megaterium), IS5 (Bacillus subtilis), IIIS9b (Bacillus subtilis), 21 (Pantoea agglomerans) and IIIS5 (Bacillus simplex). May be some of the microorganisms could be capable of producing urease, to induce precipitation of calcite that contributes to the restoration. As of now, little is known about the participation of Pantoea agglomerans in processes of biorrestauration by means of bioprecipitation of crystals of calcium carbonate and due to the fact that a good response was obtained from the test of ureasa and the crystals obtained were mainly Calcita (99 $\%$ ), this work shows the feasibility of using this native microorganisms for their activation to achieve the restoration of the worn monuments.

Key words: Limestone; bacterial bioprecipitation; Calcite; aragonite; biodeterioration y bioremediation.

\section{INTRODUCCIÓN}

La precipitación de carbonato de calcio se refiere a cuatro factores claves: 1. La concentración de carbono inorgánico disuelto, 2. El pH, 3. La concentración de iones de calcio y 4. La presencia de sitios de nucleación/o desarrollo de cristales para la nucleación. Además, diversos parámetros ambientales tales como la temperatura y salinidad de la suspensión tienen influencia sobre el proceso de precipitación (Rivadeneyra et al., 2004, Silva-Castro, et al., 2015). Diversos procesos metabólicos influencian directamente los primeros tres factores claves, mientras que las características físicas y químicas de las células bacterianas pueden hacer que estas actúen como sitios de nucleación de cristales (Hammes y Verstraete, 2002).

La vía metabólica utilizada por la bacteria tiene influencia sobre la velocidad de producción de carbonatos, y de ahí, sobre la velocidad de precipitación de carbonato de calcio. Para deposiciones sobre roca caliza, la producción de carbonatos a menudo se basaba en la utilización de ácidos orgánicos suministrados (Tiano et al., 1999) y/o la desaminación oxidativa de aminoácidos suministrados (Le Metayer-Levrel et al., 1999; Rodríguez-Navarro et al., 2003). Investigaciones recientes se han enfocado a la producción de carbonato ureolítico (Dick et al., 2006; De Muynck et al., 2008 a, b). La hidrólisis de la urea presenta un común y sencillo proceso microbiano que puede ser fácilmente utilizado para aplicaciones biotecnológicas (Adolphe et al., 1990). En contraste con otras vías la producción de carbonato por la hidrólisis de la urea puede ser fácilmente controlada. Además, es posible obtener la producción de altas concentraciones de carbonatos dentro de periodos cortos de tiempo (Castanier et al., 1999). Jroundi et al., (2010), mostraron que hay abundantes bacterias con actividad carbonatogénica presentes en la roca de los monumentos deteriorados y que son capaces de consolidar eficientemente la roca degradada por medio de la producción de un nuevo cemento de calcita y vaterita si se utiliza una adecuada solución nutricional. Hoy en día está perfectamente reconocido que el deterioro de los monumentos históricos se debe básicamente a una interacción de factores entre los que destacan: Los materiales utilizados, las condiciones ambientales y la flora microbiana existente (Ercole, et al., 2014)

Los resultados de este trabajo concuerdan con lo observado por diferentes autores en cuanto a la participación de las bacterias que habitan los monumentos en los procesos de bioprecipitación de carbonato de calcio (Jiménez-López et al., 2007 y 2008; Jroundi et al., 2010; Piñar et al., 2010;). Daskalakis, et al., 2015 y Rodríguez-Navarro et al., (2003), reportaron la importancia de los precipitados polimórficos (calcita o vaterita) sobre la eficiencia del tratamiento de biodeposición. La presencia de cristales romboédricos de calcita bien desarrollados (obtenidos con el medio M3-P, utilizado por estos autores) resultó en un más pronunciado efecto consolidante comparado con los pequeños cristales aciculares de vaterita. Estos autores concluyen que la manipulación de la composición de los medios de cultivo podría ser utilizada para controlar los procesos de biodeposición. De Muynck et al., (2009) y (2010), plantean que las diferencias en morfología podrían también ser atribuidas a las diferencias en

Nexo Revista Científica Vol. 28, No. 01, pp. 25-40/Junio 2015 
concentraciones de calcio (además de la presencia de fosfato en los medios, a como lo atribuyen Rodríguez-Navarro et al., 2003) entre los dos medios utilizados por los primeros autores mencionados. Jimenez-Lopez et al, (2008), investigaron el uso de diferentes medios para la precipitación de carbonato de calcio inducida por bacterias que habitan la roca, concluyendo que la elección de un medio de cultivo apropiado, podría prevenir alteraciones en la porosidad de la roca.

La precipitación de cristales de carbonato de calcio ocurre por nucleación heterogénea sobre la pared de la célula bacteriana (Figura 1A), una vez que la supersaturación ha sido alcanzada. Las tecnologías de biodeposición están actualmente siendo utilizadas para la consolidación de columnas de arena (Nemati y Voordouw, 2003), para reparar monumentos (Figura 1B) de roca caliza (Tiano et al., 1999; RodríguezNavarro, 2003; Dick et al., 2006), y para la remediación de pequeñas extensiones en concretos fracturados (Bachmeier et al., 2002; Quian et al., 2015). Recientemente se han publicado revisiones de lo más actual en cuanto a biocementación en concreto, sobre la precipitación bacteriana de carbonatos, los procesos químicos y su actividad de auto reparación de las bacterias incorporadas a los materiales para aplicación de calcita inducida microbiológicamente (Talaiekhozen et al, 2014; Verma et al., 2015)

Experimentos sobre el tiempo de vida útil realizados sobre monumentos de roca caliza han mostrado un efecto protector de la capa de calcita depositada por la bacteria por varios años. Se ha sugerido que un nuevo tratamiento debería ser aplicado cada diez años (Castanier et al., 1999; De Muynck et al., 2009).

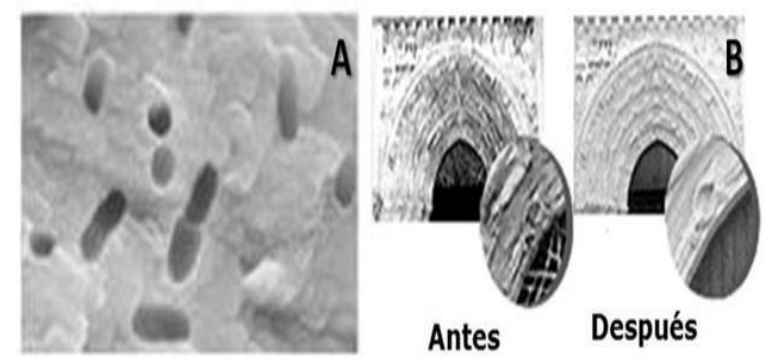

Figura 1. Composición de imágenes de la precipitación de CaCO3 (A, Tomado de De Muynck et al., 2008b), y un ejemplo de un monumento antes y después de restaurado (B, Tomado de Tiano et al., 1999).

El desgaste de los edificios es un problema generalizado que encontramos en muchas partes alrededor del mundo, ya sean hechos estos edificios de concreto así como edificios históricos hechos de rocas o ladrillos (Anne et al., 2010). En la ciudad de México existen una gran cantidad de monumentos considerados patrimonio histórico que presentan signos de daño, degradación y destrucción debido al incremento de la contaminación, factores medioambientales y biológicos. Aun cuando gran parte del deterioro es causado por microorganismos en biopelículas epilíticas, existe un completo desconocimiento acerca de su diversidad, la forma en que se implican en el proceso de biodeterioro y su uso en otras posibles aplicaciones encaminadas a la restauración de este patrimonio histórico. Considerando las dificultades que se conocen para los métodos tradicionales de cultivo, podemos concluir en la urgencia de desarrollar trabajos que involucren no sólo el uso de técnicas tradicionales de cultivo, sino las técnicas moleculares con el consecuente resultado de poder contar con aislados microbiológicos que nos permitan identificar microorganismos hasta ahora no detectados y que pudiesen estar afectando el patrimonio cultural de la nación mediante su biodeterioro. El conocimiento de la diversidad microbiana existente y la aplicación de estas técnicas novedosas, junto a otras ya en uso, nos permitirán en un futuro una mejor y mayor protección del patrimonio cultural.

En la actualidad la tecnología de producción de concreto microbiano, está emergiendo como una mejor tecnología en comparación con muchas tecnologías tradicionales, debido a sus maravillosas propiedades tales como: eco- amigables con la naturaleza, habilidad de auto reparación y la habilidad de incrementar la durabilidad de diversos materiales de construcción (Kumari, 2015)

De aquí que el presente trabajo pretende evaluar un grupo de aislados obtenidos de biopelículas epilíticas localizadas en el Castillo de Chapultepec, México, DF y determinar cuáles de estos aislados cuentan con la habilidad de formar biopelículas y en qué cantidad lo hacen, a la vez se pretende indagar sobre la

Nexo Revista Científica Vol. 28, No. 01, pp. 25-40/Junio 2015 
capacidad bioprecipitadora de cristales de carbonato de calcio con vistas a su futura utilización en la restauración de monumentos utilizando la biota autóctona.

\section{METODOLOGIA EMPLEADA}

\section{Ubicación de los sitios de los cuales se obtuvieron los aislados utilizados en este trabajo:}

Inicialmente se hizo un reconocimiento del lugar de estudio, El Castillo de Chapultepec ubicado en lo alto del cerro del mismo nombre, en el centro del Bosque de Chapultepec, situado en la ciudad de México y se definieron los mejores puntos para la recolección de las muestras considerando los diferentes aspectos climatológicos que intervienen en la formación de la biopelícula como son: exposición a la luz solar, temperatura, incidencia del aire, humedad, entre otros (Videla et al., 2003), además de la contaminación ambiental presente en los alrededores del castillo. Para el aislamiento e identificación de microorganismos a partir de biopelículas epilíticas de superficies asociadas al Castillo de Chapultepec (Páramo et al., 2011 y Páramo, 2012), se eligieron tres puntos en la zona del Castillo, los cuales fueron: puntos I y II relacionados con los cimientos del muro perimetral del Castillo ubicados a unos 100 y 150 metros de distancia respectivamente de la puerta de ingreso principal a Chapultepec, y un punto III ubicado en el monumento a la madre patria en el patio lateral del Castillo, en el cual se observó deterioro de la roca, grandes desprendimientos de la misma y zonas fracturadas (Figuras 2 y 3 ).

El modelo analizado consta de un cilindro de radio $\mathrm{E}$ y altura $\mathrm{H}$, el cual tiene un impulsor radial en la parte superior, y su envolvente y fondo se encuentran fijos. En el interior del cilindro se tiene un fluido newtoniano, viscoso e incompresible. El impulsor se mueve a una velocidad angular constante $\Omega$ y se estudian cinco factores de forma (H/E): 1.0, 1.25, 1.5, 1.75 y 2.0.
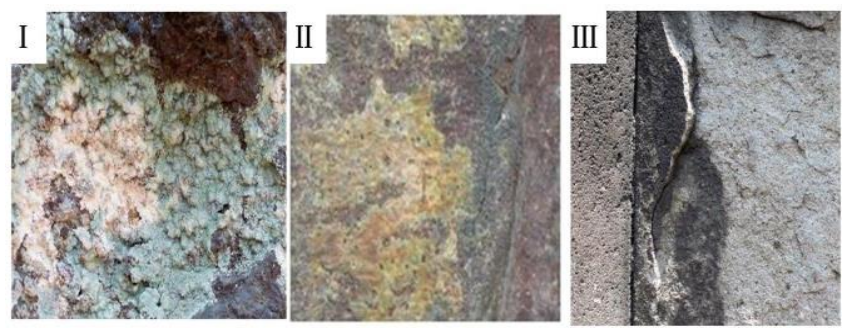

Figura 2. Biopelículas muestreadas en el Castillo Chapultepec. I, Biopelícula localizada en el punto I ubicado a 100 metros de la entrada principal al Castillo; II Biopelícula localizada en el punto II ubicado a 150 metros de la entrada principal al Castillo mostrando biomineralización y III, Biopelícula localizada en un monumento al interior del Castillo en el que se muestran zonas fracturadas.

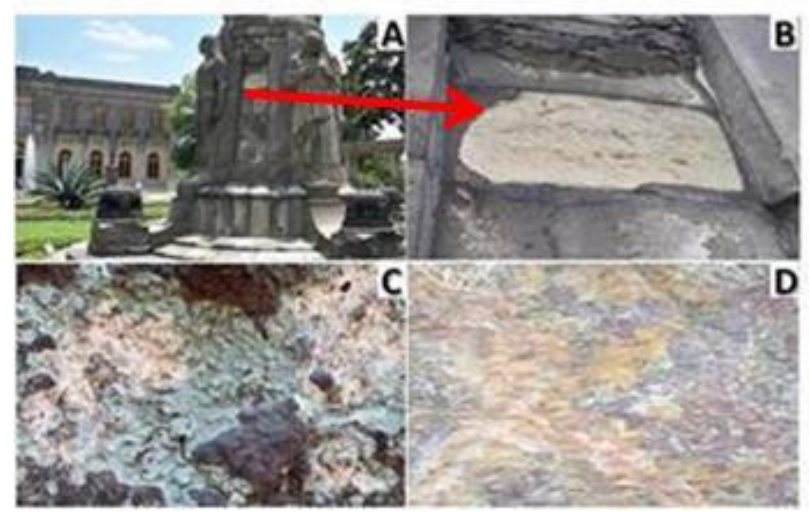

Figura 3. Monumento a la Madre Patria (A), Deterioro observado en el monumento (B), Biopelículas observadas sobre las rocas de los muros perimetrales $(C)$ y Biomineralización observada sobre las rocas de los muros perimetrales del Castillo de Chapultepec (D). 


\section{Determinación de aislados con capacidad formadora de biopelículas:}

Previo al desarrollo de cada experimento de formación de biopelículas (Necesarios para definir los aislados a ensayar en la bioprecipitación de carbonatos de calcio), se tomó una asada de cada cepa bacteriana (Cuadro 1) para ser crecida en $10 \mathrm{~mL}$ de medio líquido LB (Luria Bertani, Miller) y fueron puestas a crecer a $30^{\circ} \mathrm{C}$ (a condiciones ambientales del cuarto de cultivo) con agitación moderada de 50 rpm (Cole Parmer Rocking platform, modelo 625E de EEUU) por alrededor de 18 a 20 horas en condiciones del cuarto de cultivo (Ambientales). Para la determinación del potencial de formación de biopelículas y por ende determinar cómo influye el ambiente de la biopelícula en la biopreciptación, se consideró que según el índice de McFarlan A (Absorbancia): 0.09-0.1 corresponden aproximadamente a 1.0E+08 UFC (Unidades Formadoras de Colonias). De esta forma se evaluaron las 30 cepas (Cuadro 1) a las 24 y 48 horas de incubación en medio líquido LB (Luria Bertani, Miller).

De cada una de las 30 cepas (Cuadro 1) a ser ensayadas y que previamente fueron crecidas en medio liquido LB por 18 a 20 horas (Figura 6A), se tomaron $0.1 \mathrm{~mL}$ para ser transferidos a placas de micro titulación de PVC (Becton Dickinson labware, Franklin Lakes, NJ, EEUU), y se siguió el protocolo propuesto por Djordjevic et al., (2002) con algunas modificaciones que se describen a continuación. Para cada cepa se hicieron 5 réplicas y se utilizó como blanco la solución del medio de cultivo. Las placas fueron lavadas con alcohol al $70 \%$ y secadas en condiciones de cámara de flujo vertical. Una vez inoculadas las placas con las suspensiones bacterianas y habiéndose hecho por duplicado para ser leídas sus absorbancias a las 24 horas y a las 48 horas en un espectrofotómetro Jenwall 6300 a $540 \mathrm{~nm}$ (LabTech, instrumentation, EEUU) se pusieron a incubar a $30^{\circ} \mathrm{C}$ (Incubadora Riossa, Meriequipos, México). Los aislados del cuadro 1 fueron previamente obtenidos de biopelículas epilíticas (Figuras 2 y 3 ) localizadas en el Castillo Chapultepec e identificados por via microbiológica y molecular (Páramo et al., 2011 y Páramo, 2012)

Las placas fueron lavadas con alcohol al $70 \%$ y secadas en condiciones de cámara de flujo vertical. Una vez inoculadas las placas con las suspensiones bacterianas y habiéndose hecho por duplicado para ser leídas sus absorbancias a las 24 horas y a las 48 horas en un espectrofotómetro Jenwall 6300 a $540 \mathrm{~nm}$ (Lab-Tech, instrumentation, EEUU) se pusieron a incubar a $30^{\circ} \mathrm{C}$ (Incubadora Riossa, Meriequipos, México) . Transcurrido el tiempo de incubación tanto para 24 como para 48 horas, las placas fueron llevadas al lector de micro platos BIO-RAD modelo 550 (Meriequipos, BIO-RAD, México) y se determinó la absorbancia a $540 \mathrm{~nm}$.

Posteriormente se realizó el proceso de lavado (Figura 4A) de todas las bacterias que hubiesen quedado libres y por tanto no se hayan adherido a las paredes de la placa, por medio de tres lavados sucesivos con agua destilada y secándose en cámara de flujo por espacio de 30 minutos. Finalizados los treinta minutos se adicionaron $150 \mu \mathrm{L}$ de cristal violeta al $0.1 \%$ a cada pozo y se dejó reposar por 15 minutos para facilitar el teñido de las bacterias adheridas a las paredes de los pozos (Figura 4B). Se lavó nuevamente de 3 a 4 veces con agua destilada y se secó a temperatura ambiente por 15 minutos. Se adicionaron $150 \mu \mathrm{L}$ de etanol absoluto para permitir el desteñido de las bacterias y se dejó en reposó por 15 minutos más, finalizando con la lectura nuevamente de la absorbancia a $540 \mathrm{~nm}$ de las micro platos utilizando en este caso como blanco el etanol absoluto (Figura 4C). Dado que ha sido mencionado (Djordjevic et al., 2002), que la adición de azucares incrementa el crecimiento y favorece la formación de la biopelícula, se repitió el mismo experimento para aquellos aislados que resultaron mejores formadores de biopelículas sin la adición de azucares, pero considerando adicionar a los mismos al 0.1 $\%$ de azúcar. 
Leandro Alberto Páramo Aguilera, José Alberto Narváez Zapata y Benjamín Otto Ortega Morales

Cuadro 1. Aislados utilizados (30) para ensayar los procesos de formación de biopelículas y bioprecipitación de cristales de carbonato de calcio. I, II y III: Referido a los puntos muestreados según figuras 2 y 3.

\begin{tabular}{|c|c|c|c|}
\hline \multirow{2}{*}{ Código LBI } & \multicolumn{3}{|c|}{ Muestra } \\
\hline & 1 & II & III \\
\hline IS4 & $x$ & & \\
\hline IS5 & $x$ & & \\
\hline IIIS9b & & & $x$ \\
\hline IS3 & $x$ & & \\
\hline IIIS10 & & & $x$ \\
\hline IS16 & $x$ & & \\
\hline IIS17 & & $x$ & \\
\hline IIS15a & & $x$ & \\
\hline IIIS9a & & & $x$ \\
\hline IS12 & $x$ & & \\
\hline IIIS5 & & & $x$ \\
\hline 32 & & & $x$ \\
\hline IIS12 & & $x$ & \\
\hline IIS3 & & $x$ & \\
\hline 31 & & & $x$ \\
\hline IIS9 & & $x$ & \\
\hline IIS2 & & $x$ & \\
\hline IIS10 & & $x$ & \\
\hline IS8 & $x$ & & \\
\hline IIIS4 & & & $x$ \\
\hline IIS1 & & $x$ & \\
\hline IIIS9 & & & $x$ \\
\hline IS2 & $x$ & & \\
\hline IS6 & $x$ & & \\
\hline 21 & & $x$ & \\
\hline IIS4 & & $x$ & \\
\hline 27 & & $x$ & \\
\hline IS17a & $x$ & & \\
\hline IS1 & $x$ & & \\
\hline IS17 & $x$ & & \\
\hline
\end{tabular}

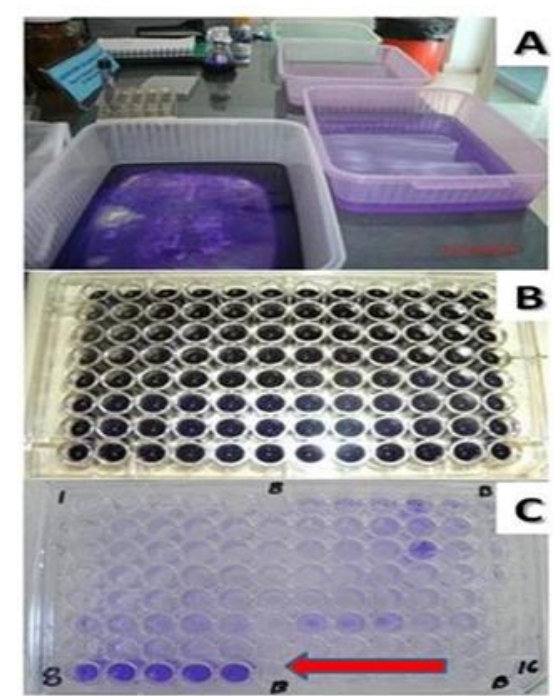

Figura 4. Proceso de lavado y teñido de las biopelículas. Charolas utilizadas para el proceso de lavado de las placas (A), Proceso de teñido con cristal violeta (B), Reposo de las muestras y (C) Evidencia de la formación de biopelícula señaladas con una flecha. 


\section{Desarrollo de la prueba de ureasa:}

Para el desarrollo de la prueba de ureasa (Indica posible mecanismo de bioprecipítación seguido por un microorganismo) se siguieron los protocolos recomendados por Dick et al., (2006); De Muynck et al., (2008a, b) con algunas modificaciones. Para esto se prepararon $150 \mathrm{~mL}$ de un medio compuesto por $3 \mathrm{~g}$ de medio de fermentación conteniendo rojo fenol como indicador, urea $3 \mathrm{~g}, 0.3 \mathrm{~g}$ de fosfato potásico monobásica, $0.15 \mathrm{~g}$ de glucosa con $2.4 \mathrm{~g}$ de agar-agar. Todos los componentes fueron disueltos en 125 $\mathrm{mL}$ de agua destilada salvo la urea y la glucosa que se disolvieron en $\operatorname{los} 25 \mathrm{~mL}$ de agua restantes. La urea y la glucosa disueltos en $25 \mathrm{~mL}$ de agua fueron esterilizadas por filtración (Filtros millipore de 0.22 $\mu \mathrm{m})$, mientras que los demás componentes disueltos en $125 \mathrm{~mL}$ de agua, fueron esterilizados en autoclave (AESA, MOD.CV 250) por 15 minutos a $120^{\circ} \mathrm{C}$ y 1 atm de presión. Ambos medios se juntaron en cámara de flujo laminar (Class IIA/B3 Biological Safety Cabinet) y fueron distribuidos en tubos microbiológicos a razón de $10 \mathrm{~mL}$ por cada tubo y puestos a solidificar formando cuñas. Se seleccionaron los 12 aislados mejores formadores de biopelículas para conducir la prueba de ureasa. Finalmente las cepas seleccionadas fueron puestas a incubar durante ocho días a $30^{\circ} \mathrm{C}$ a condiciones de cuarto de cultivo, durante los cuales se verificaron periódicamente para ir observando el cambio de coloración como un indicativo de la liberación de la ureasa que basifíca el medio utilizado.

\section{Bioprecipitación de cristales carbonato de calcio:}

Para la bioprecipitación de cristales de carbonato de calcio, se utilizó el medio LB suplementado con agar-agar, el cual fue preparado con adición de carbonato de calcio al $0.2 \%$, vaciado en placas de Petri y dejadas solidificar para su inoculación posterior con cada una de las cepas de los 12 aislados a los cuales se les realizó la prueba de ureasa previamente. Para cada cepa en estudio, se sembraron 5 réplicas y se utilizó como control una placa conteniendo el medio con carbonato de calcio pero sin la adición de microorganismos. Una vez finalizada la siembra en placas, las mismas fueron puestas en incubación a $30^{\circ} \mathrm{C}$ (En condiciones de cuarto de cultivo) durante un periodo de 22 días durante los cuales se realizaron verificaciones constantes al microscopio de luz (Nikon Eclipse E200, Japón) con el objetivo $10 \mathrm{X}$ y se tomaron fotografías de los cristales (Cámara Nikon DS-Fi1 y equipo de captura de imágenes Nikon Digital Sight, EEUU) formados a través del tiempo a fin de documentar su proceso de formación para cada una de las cepas con el transcurso del tiempo, siguiendo una adaptación del proceso de precipitación de cristales propuesto por Laiz et al., (2009).

Finalizado el periodo de incubación se dio inicio al proceso de cosecha de los cristales para cada una de las cepas en estudio. Para esto se retiraron los cultivos de la incubadora y con una espátula metálica se hicieron cortes al agar conteniendo los microorganismos y los cristales para ser llevados a frascos Erlenmeyer tal y como se muestra en las figuras 5A y 5B. Una vez trasladado el agar de todas las placas inoculadas a los erlenmeyer, se adicionó suficiente agua destilada previamente calentada en horno de microondas y nuevamente se puso en microondas hasta lograr la fundición completa del agar. Una vez fundido el agar, el frasco erlenmeyer se retiró del microondas y fue puesto en reposo para precipitar los carbonatos en excesos junto a los cristales durante un tiempo no menor de 15 minutos. Transcurrido este tiempo, se retiró el sobrenadante del frasco erlenmeyer y se adicionó agua destilada limpia y fresca para iniciar un proceso de tres lavados con 15 minutos de precipitación en cada caso (Figs. 5C y 5D). Finalizado el proceso de lavado, los cristales y el exceso de carbonato fue retirado del erlenmeyer por medio de pipetas Pasteur y envasado en viales (Figura 5E, Proceso desarrollado en el Laboratorio de Biotecnología Ambiental de la Universidad Autónoma de Campeche). Finalmente fueron trasladados para su posterior análisis por difracción de rayos X (Se muestran parcialmente en este artículo) y microscopia electrónica de barrido (Datos no mostrados), los cuales fueron desarrollados en calidad de servicios externos por los laboratorios del Centro de Investigación Científica de Yucatán (CICY de Mérida, Yucatán, México). 


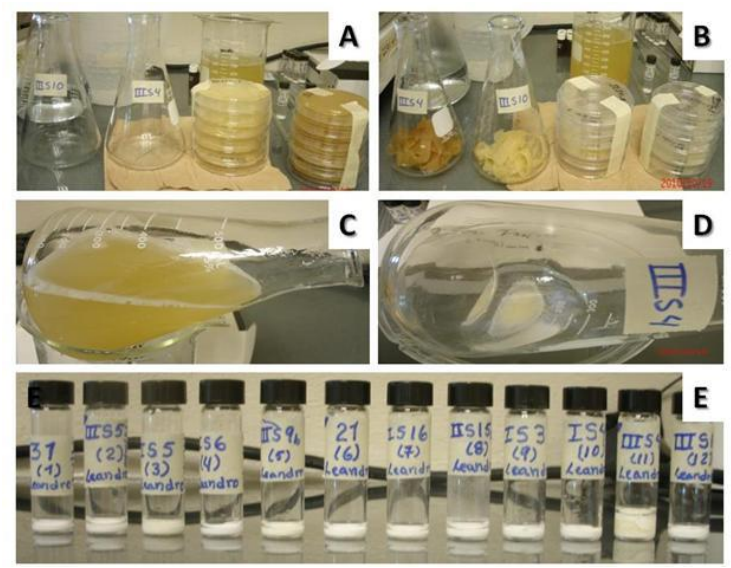

Figura 5. Proceso de obtención de cristales: Inicio del proceso de cosecha de cristales (A), Transferencia a Erlenmeyer (B), Reposo del agar fundido y precipitación (C), Lavado de cristales con agua destilada (D), Cristales listos para análisis posteriores (E).

\section{RESULTADOS}

De cada una de las cepas crecidas en tubo a las 18 horas aproximadamente se tomaron $100 \mu \mathrm{L}$ (Figura 6A) y fueron llevados a micro placas previamente preparadas según se detalló en la metodología experimental, utilizándose como blanco el medio LB sin inocular y puestos a incubar por 24 y 48 horas el duplicado de las placas.

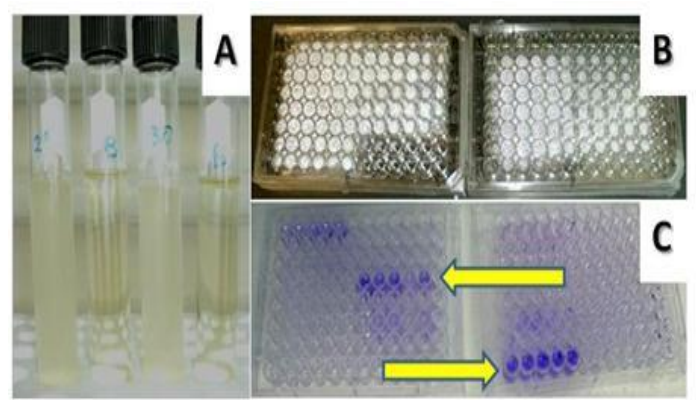

Figura 6. Crecimiento de bacterias en diferentes momentos del proceso de formación de biopelícula a 24 horas. (A) Crecidas en tubo, (B) Crecidas en micro placa y (C) Cepas que muestran formación de biopelícula. Las flechas indican los aislados con mejor formación de biopelícula.

Finalizadas las primeras 24 horas se llevaron las placas (Figuras 6B y 6C) al lector de microplacas BIORAD 550 y se leyó la absorbancia para cada uno de los pozos. En micro placa a las 24 horas predominó el crecimiento de bacterias aisladas de los puntos uno y dos de los muestreados, mientras que en tubo se obtuvo crecimiento de aislados de los diferentes puntos. Una vez leída la absorbancia (Datos no mostrados) se procedió a lavar las bacterias no adheridas a la superficie de los pozos y a teñir con cristal violeta. Después del teñido fue posible observar biopelículas adheridas a la superficie para las cepas: IS4 (Bacillus subtilis), IS16 (Bacillus subtilis), IIS15a (Bacillus cereus), IIIS10 (Bacillus subtilis), IIIS4 (Bacillus megaterium) y IIIS5 (Bacillus simplex), siendo las 3 mejores en cuanto a formar biopelículas a las 24 horas las cepas IS16 (Bacillus subtilis), IIS15a (Bacillus cereus) y la IIIS10 (Bacillus subtilis) (Figura 6C).

A 48 horas de incubación (Figura 7), las cepas que reportan un mayor crecimiento en microplaca fueron: 27 (Stenotrophomonas sp.), 21 (Pantoea agglomerans), IIS1 (Bacillus psychrodurans), IIS12 (Bacillus simplex) y 32 (Bacillus simplex).

Las cepas que reportan un mayor crecimiento a 48 horas no coinciden en general con las obtenidas en iguales condiciones, pero leídas a las 24 horas, salvo para las cepas 21 (Pantoea agglomerans) y IIS1

Nexo Revista Científica Vol. 28, No. 01, pp. 25-40/Junio 2015 
(Bacillus psychrodurans). Esto puede explicarse según lo que se ha observado en el crecimiento de las cepas que en su mayoría crecen entre las 18 y 24 horas en tubo, salvo algunos casos que requieren más de 24 horas para que se observe un completo crecimiento entre las que están las cepas: 27 (Stenotrophomonas sp.), IIS12 (Bacillus simplex) y 32 (Bacillus simplex). Se lavaron las placas y luego del teñido de las mismas (Figura 7B) en las que se observó crecimiento de biopelícula (Figura 7C) para las cepas: IS16 (Bacillus subtilis), IS6 (Pantoea agglomerans), IS3 (Bacillus subtilis), IS5 (Bacillus subtilis), 21 (Pantoea agglomerans), IIS15a (Bacillus cereus), IIIS9b (Bacillus subtilis), 31 (Bacillus simplex), IIIS10 (Bacillus subtilis), IIIS4 (Bacillus megaterium) y IIIS5 (Bacillus simplex).

Finalmente, la lectura de la absorbancia para cuantificar la biopelícula formada, arroja que las 3 mejores cepas formadoras de biopelículas a las 48 horas fueron: IS16 (Bacillus subtilis), IIS15a (Bacillus cereus) y IIIS9b (Bacillus subtilis) (resultados mostrados en Cuadro 2; Figuras 6C y 7C). El siguiente cuadro (Cuadro 2) reporta los resultados obtenidos tanto para el experimento sin glucosa como para el mismo experimento pero con la adición de glucosa al $0.1 \%$ y considerando únicamente a las tres cepas que resultaron ser mejores formadoras de biopelículas tanto a 24 como a 48 horas.

Del análisis de los resultados del cuadro 2, es posible observar que en la placa (o microplaca) tenemos una mayor absorbancia en comparación con el valor que se obtiene para la absorbancia en la biopelícula. Este último valor (en la biopelícula) nos da una idea más real de cuantos microorganismos en UFC del total, realmente están formando biopelículas y estos son los que nos interesan a efectos de la investigación porque potencialmente pudiese estar influyendo el proceso de bioprecipitación de cristales de carbonato de calcio. Además, se comprobó que la glucosa en sentido general si contribuye a incrementar el crecimiento microbiano en las diferentes fases, aunque este crecimiento está en dependencia del tipo de microorganismo de que se trate y el análisis de nuestros resultados parece indicar que este crecimiento no se traduce en igual forma a la adhesión y formación de biopelículas, por lo que mayores investigaciones serán requeridas para dilucidar el papel de los azucares con respecto a la adherencia y formación de la biopelícula como tal.
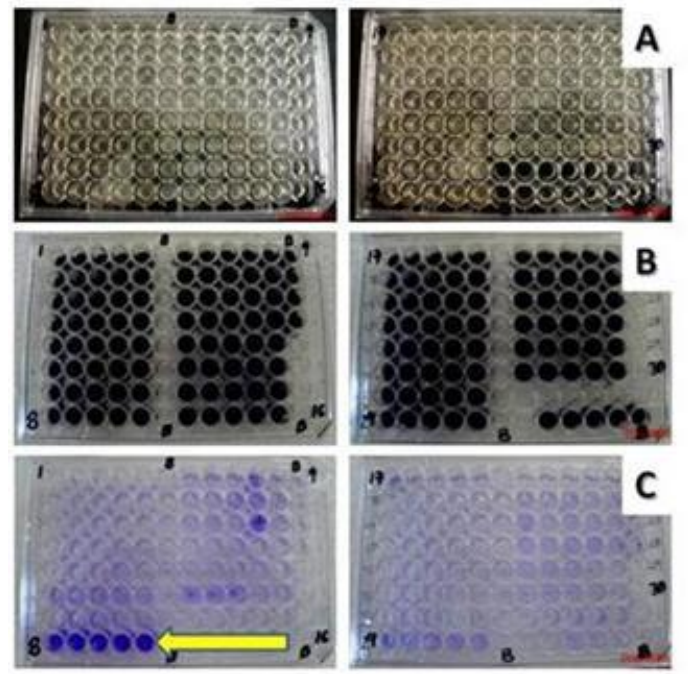

Figura 7. Proceso de formación de la biopelícula en micro placa a 48 horas de incubación. (A) Recién retiradas de incubación. (B) Durante el teñido con cristal violeta. (C) Cepas que forman biopelícula. La flecha indica los aislados con mejor formación de biopelícula.

Para dar inicio a la bioprecipitación de cristales de carbonatos de calcio, se llevó a cabo primeramente la prueba de Ureasa para cada una de las 12 cepas que dieron buenos resultados en general en el proceso de producción de biopelículas (tanto a las 24 como a las 48 horas, cuadro 3). Esto nos estaría indicando cuales de los microorganismos potenciales formadores de biopelículas y por ende buenos candidatos a utilizarse como bioprecipitadores, pudieran estar utilizando la vía de la ureasa para llevar a cabo la bioprecipitación, a la vez que nos da una idea de en qué cuantía se desarrolla este proceso por cada uno de los microorganismos en estudio (Chaurasia \& Visht, 2014). Paralelamente al desarrollo de la prueba 
de ureasa, se desarrolló el experimento de bioprecipitacion de cristales de carbonato de calcio con los mismos aislados para cada experimento en particular.

Cuadro 2. Valores de absorbancias promedios y sus correspondientes desviaciones estándar, durante todo el proceso de formación de biopelícula, desde el crecimiento en tubo, pasando por microplaca hasta el biofilm a 24 y 48 horas respectivamente para la fase 1 (sin glucosa) y 2 (con $0.1 \%$ de glucosa).

\begin{tabular}{|c|c|c|c|c|c|c|}
\hline $\begin{array}{l}\text { Fas } \\
\text { e }\end{array}$ & Cepas & Inicial & \multicolumn{2}{|c|}{$\begin{array}{l}\text { En placa a } \\
\text { As40nm }\end{array}$} & \multicolumn{2}{|c|}{$\begin{array}{l}\text { En biopelicula } \\
\text { a As\$0nm }\end{array}$} \\
\hline \multirow[t]{4}{*}{1} & & & $24 \mathrm{~h}$ & $48 \mathrm{~h}$ & $24 \mathrm{~h}$ & $48 \mathrm{~h}$ \\
\hline & $\begin{array}{l}\text { Cepa } \\
\text { IS16 }\end{array}$ & 0.191 & $\begin{array}{l}0.94 \\
\pm \\
0.12\end{array}$ & $\begin{array}{l}0.54 \pm \\
0.08\end{array}$ & $\begin{array}{l}0.02 \\
\pm \\
0.21\end{array}$ & $\begin{array}{l}0.01 \\
\pm \\
0.02\end{array}$ \\
\hline & $\begin{array}{l}\text { Cepa } \\
\text { IIS15a }\end{array}$ & 1.278 & $\begin{array}{l}0.20 \\
\pm \\
0.06\end{array}$ & $\begin{array}{l}0.62 \pm \\
0.17\end{array}$ & $\begin{array}{l}0.04 \\
\pm \\
0.06\end{array}$ & $\begin{array}{l}0.07 \\
\pm \\
0.05\end{array}$ \\
\hline & $\begin{array}{l}\text { Cepa } \\
\text { IIIS10 }\end{array}$ & 0.197 & $\begin{array}{l}0.49 \\
\pm \\
0.21\end{array}$ & $\begin{array}{l}0.53 \pm \\
0.11\end{array}$ & $\begin{array}{l}0.04 \\
\pm \\
0.02\end{array}$ & $\begin{array}{l}0.06 \\
\pm \\
0.02\end{array}$ \\
\hline \multicolumn{7}{|l|}{2} \\
\hline & $\begin{array}{l}\text { Cepa } \\
\text { IS16 }\end{array}$ & 0.135 & $\begin{array}{l}0.05 \\
\pm \\
0.48\end{array}$ & $\begin{array}{l}0.08 \pm \\
0.14\end{array}$ & $\begin{array}{l}0.01 \\
\pm \\
0.005\end{array}$ & $\begin{array}{l}0.05 \\
\pm \\
0.00 \\
7\end{array}$ \\
\hline & $\begin{array}{l}\text { Cepa } \\
\text { IIS15a }\end{array}$ & 1.278 & $\begin{array}{l}0.5 \\
\pm \\
0.03\end{array}$ & $\begin{array}{l}0.39 \pm \\
0.07\end{array}$ & $\begin{array}{l}0.05 \\
\pm \\
0.003\end{array}$ & $\begin{array}{l}0.07 \\
\pm \\
0.00 \\
9\end{array}$ \\
\hline & $\begin{array}{l}\text { Cepa } \\
\text { IIIS10 }\end{array}$ & 1.278 & $\begin{array}{l}1.05 \\
\pm \\
0.05\end{array}$ & $\begin{array}{l}1.35 \pm \\
0.03\end{array}$ & $\begin{array}{l}0.02 \\
\pm \\
0.013\end{array}$ & $\begin{array}{l}0.08 \\
\pm \\
0.01\end{array}$ \\
\hline
\end{tabular}

Los resultados de la prueba de ureasa (Figura 8) mostraron que la cepa 21 (Pantoea agglomerans) a las 16 horas de incubación ya mostraba la presencia de ureasa y otras como IS16, IIIS5, IS3 y IS5 lo hacen hasta los cinco días de incubación. Para este tiempo de incubación, la cepa que antes mostró ser positiva a la ureasa a las 16 horas, se puede ver que ha liberado mucha más ureasa ya a los cinco días (Datos no mostrados). La Figura 8, nos muestra que las mismas cepas que antes ya habían liberado ureasa son las mismas que aparecen reportadas a los ocho días, pero con mucha más liberación de esta enzima (Figura 8B). Esta misma Figura muestra que a los ocho días, las que ya no habían virado positivamente a la ureasa se agrupan en dos partes: Las que crecieron en el medio y dan negativas a la producción de ureasa (Figura 8C) y las que no crecieron en el medio de trabajo (Figura 8D).

Aunque la cepa 21 (Pantoea agglomerans) dio resultados muy buenos a las 16 horas en cuanto a la producción de ureasa y algunas no crecieron en el medio, o bien crecieron pero no produjeron ureasa, se recomendó no descartar ninguna de ellas, hasta tanto se tenga mayor información sobre esta prueba (Mayores investigaciones hayan dilucidado la influencia de esta vía en la bioprecipitación). Los resultados con Pantoea agglomerans resultan muy alentadores si se considera que hasta donde conocemos al día de hoy, no se han reportado resultados de este tipo para con esta especie bacteriana. 


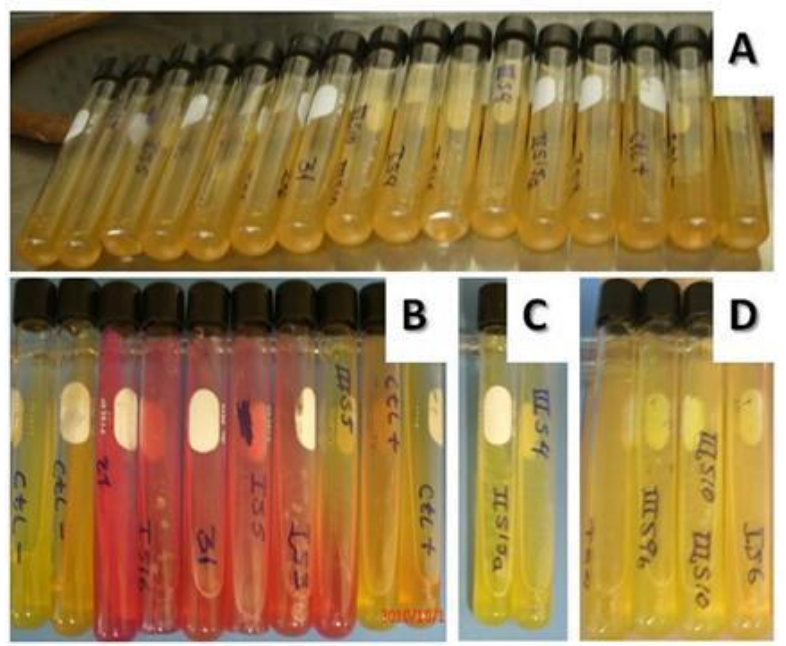

Figura 8. Resultados finales de la prueba de ureasa. A. Tubos con medio LB recién inoculados. B. A los ocho días de incubación. C. Cultivos que crecen en el medio pero que no muestran presencia de ureasa a los ocho días de incubación. D. Cultivos que no crecieron a los 8 días de inoculación.

En el caso de la bioprecipitación de cristales de carbonato de calcio, los mismos aislados que antes fueron sometidos a la prueba de ureasa fueron sometidos a esta prueba. Los resultados observados en un microscopio Nikon Eclipse E200 con un objetivo de 10X a partir del tercer día se muestran en las Figuras 9 para 3 de las mejores cepas en cuanto a formar biopelículas a 24 y 48 horas respectivamente.

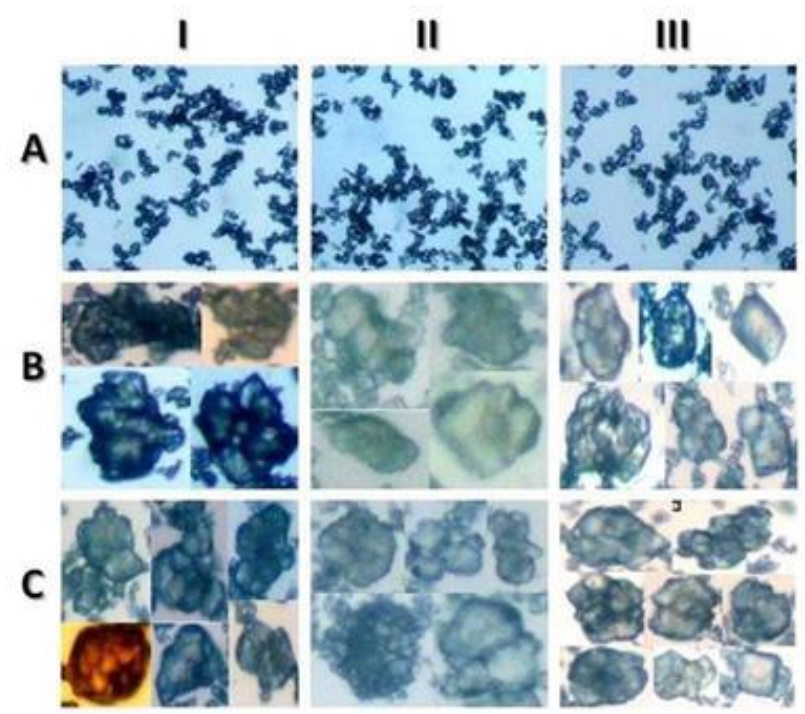

Figura 9. Cristales de carbonato de calcio a los 15 y 22 días respectivamente para los mejores formadores de biopelículas. AI. Control sin inocular, BI y CI, Cepa IS16 (Bacillus subtilis) a los 15 y 22 días; AII. Control sin inocular, BII y CII. Cepa IIS15a (Bacillus cereus) a los 15 y 22 días; AIII. Control sin inocular, BIII y CIII. Cepa IIISIO (Bacillus subtilis) a los 15 y 22.

La figura anterior nos muestra los cristales de carbonato de calcio para las tres cepas que mejor formaron biopelículas, en ella se puede ver la presencia de cristales de diferentes colores y tamaños, además de que no pudo verse diferencia aparente entre los resultados de los cristales a los 15 días y a los 22 días respectivamente, tiempo en que se decidió detener el desarrollo del experimento.

Hasta aquí los resultados se resumen en el cuadro 3. En este cuadro se pueden ver los 12 aislados que dieron buenos resultados en cuanto a formación de biopelículas (tanto a 24 como a 48 horas), por ende los aislados que fueron sometidos tanto a las pruebas de ureasa, como de bioprecipitación de carbonatos de calcio. 
La selección como mejores bioprecipitadoras, se hizo inicialmente chequeando la capacidad de producir cristales de $\mathrm{CaCO} 3$ y la cantidad de cristales que se logró recolectar de cada una de ellas después de la cosecha. Cristales y tamaños diferentes fueron observados, sin diferencia visual apreciable a los 15 y 22 días respectivamente. La cosecha de los cristales de carbonato de calcio, previo a ser enviados a realizarle análisis de microscopia electrónica de barrido y de difracción de rayos $\mathrm{X}$ (Datos parciales se muestran aqui), se realizó tal y como se mostró en la metodología experimental en la Figura 5. Una etapa posterior de trabajo, considera seleccionar los mejores biopreciptadores de $\mathrm{CaCO} 3$, ya no solo chequeando capacidad de bioprecipitación y cantidad cosechada (antes de contar con la información de difracción de rayos X y de microcopia electrónica de barrido) sino tomando en cuenta los resultados de estos últimos análisis (una pequeña parte se muestra en el cuadro 3), cuya morfología y tipo predominante de cristal nos guiará a aquellos microorganismos con los que se continuará trabajando para la futura restauración en los edificios patrimoniales. Para este análisis se deberá considerar la capacidad de los aislados en estudio para formar cristales de carbonato de calcio (CaCO3), la extensión de los procesos de precipitación (duración) y la forma (geometría) de los cristales producidos. Además se deberá tener en cuenta que la forma y el tamaño de los cristales formados dependen tanto de la cepa bacteriana como de las condiciones a las cuales se desarrolla. Todo esto ha sido ampliamente discutido por diversos autores (Ercole, et al., 2014), coincidiendo en indicar la importancia de estos procesos para la restauración de monumentos pertenecientes al patrimonio histórico.

Cuadro 3. Características bioquímicas y de formación de cristales de los aislamientos formadores de biopelículas a las 24 y 48 horas en microplacas

\begin{tabular}{|c|c|c|c|c|c|c|c|c|c|}
\hline \multirow[t]{2}{*}{ Código } & \multirow[t]{2}{*}{ Identidad } & \multirow{2}{*}{$\begin{array}{l}\text { Formación } \\
\text { de } \\
\text { biopelícula } \\
\text { (UFC/mL) }\end{array}$} & \multirow[t]{2}{*}{$\begin{array}{l}\text { Actividad } \\
\text { de ureasa } \\
\text { (h) }\end{array}$} & \multicolumn{3}{|c|}{$\begin{array}{c}\text { Bioprecipitación de } \\
\operatorname{CaCo}_{3}(\%)\end{array}$} & \multicolumn{3}{|c|}{$\begin{array}{c}\text { Punto } \\
\text { Muestreado al } \\
\text { que pertenece }\end{array}$} \\
\hline & & & & Calcita & Aragonita & Whewellita & I & II & III \\
\hline IS4 & $\begin{array}{c}\text { Bacillus } \\
\text { subtilis }\end{array}$ & $\begin{array}{l}1.3 \mathrm{E} 08 \pm \\
0.0971 *\end{array}$ & SCEM & 99.17 & 0.63 & 0.20 & $\mathrm{X}$ & & \\
\hline IS5 & B. subtilis & $\begin{array}{l}4.8 \mathrm{E} 07 \pm \\
0.0388 * *\end{array}$ & 5 días & 99.15 & 0.69 & 0.16 & $\mathrm{X}$ & & \\
\hline IIIS9b & B. subtilis & $\begin{array}{l}5.2 \mathrm{E} 08 \pm \\
0.1186 * *\end{array}$ & BCEM & 98.97 & 0.74 & 0.29 & & & $X$ \\
\hline IS3 & B. subtilis & $\begin{array}{l}6.6 \mathrm{E} 07 \pm \\
0.0397 * *\end{array}$ & 48 horas & 99.27 & 0.73 & 0.0 & $\mathrm{X}$ & & \\
\hline IIIS10 & B. subtilis & $\begin{array}{l}4.9 \mathrm{E} 07 \pm \\
0.2157 *\end{array}$ & BCEM & 99.49 & 0.41 & 0.1 & & & $X$ \\
\hline IS16 & B. subtilis & $\begin{array}{l}9.4 \mathrm{E} 07 \pm \\
0.2143 *\end{array}$ & 48 horas & 99.49 & 0.51 & 0.0 & $\mathrm{X}$ & & \\
\hline IIS15a & B. cereus & $\begin{array}{l}2.34 \mathrm{E} 07 \pm \\
0.0636 *\end{array}$ & BCEM & 99.26 & 0.59 & 0.15 & & $\mathrm{X}$ & \\
\hline IIIS5 & B. simplex & $\begin{array}{l}1.0 \mathrm{E} 07 \pm \\
0.0368 *\end{array}$ & 5 días & 99.01 & 0.99 & 0.0 & & & $X$ \\
\hline 31 & B. simplex & $\begin{array}{l}4.8 \mathrm{E} 07 \pm \\
0.0388 * *\end{array}$ & 5 días & 99.12 & 0.60 & 0.28 & & & $\mathrm{X}$ \\
\hline IIIS4 & $\begin{array}{l}B . \\
\text { megaterium }\end{array}$ & $\begin{array}{l}2.2 \mathrm{E} 07 \pm \\
0.007 *\end{array}$ & BCEM & 99.35 & 0.55 & 0.1 & & & $\mathrm{X}$ \\
\hline IS6 & $\begin{array}{l}\text { Pantoea } \\
\text { agglomerans }\end{array}$ & $\begin{array}{l}1.1 \mathrm{E} 07 \pm \\
0.0024 * *\end{array}$ & SCEM & 99.13 & 0.67 & 0.20 & $X$ & & \\
\hline 21 & $\begin{array}{l}P . \\
\text { agglomerans }\end{array}$ & $\begin{array}{l}2.0 \mathrm{E} 07 \pm \\
0.0029 * *\end{array}$ & 16 horas & 99.5 & 0.34 & 0.16 & & $\mathrm{X}$ & \\
\hline
\end{tabular}

*. Mejores aislados en cuanto a formar biopelículas a las 24 horas en microplaca.

**. Mejores aislados en cuanto a formar biopelículas a las 48 horas en microplaca.

BCEM. Buen crecimiento en el medio sin cambio de coloración a los 8 días.

SCEM. No se observó crecimiento en el medio utilizado a los ocho días de incubación.

Nexo Revista Científica Vol. 28, No. 01, pp. 25-40/Junio 2015 


\section{CONCLUSIONES Y PERSPECTIVAS FUTURAS}

Las comunidades microbianas que se desarrollan asociadas a los sustratos de roca son en parte responsables del deterioro químico y físico de la misma y alteran a través de diferentes mecanismos la apariencia estética y la integridad física del material (Krumbein, 1988) con la consecuente formación de suciedad y transformación de minerales (Eckardt, 1985). La excreción de enzimas y ácidos inorgánicos y orgánicos disuelve los componentes estructurales del sustrato mineral, contribuyendo a los procesos de deterioro (Warscheid et al., 1988). La biopelícula también es un microambiente donde la precipitación puede ser facilitada o inhibida alrededor de escalas micro espaciales (por ejemplo $\mu \mathrm{m}$ a $\mathrm{mm}$ ) y exhiben alguna organización espacial. La biopelícula y su matriz EPS (Sustancias poliméricas extracelulares) asociada, por tanto, sirve como un punto de inicio útil para investigar como las moléculas orgánicas influencian los procesos de precipitación (Decho, 2010, Ercole, et al., 2014).

Mediante este trabajo se pudo constatar que a las 24 y 48 horas respectivamente, las mejores cepas en cuanto a formar biopelículas fueron: IS16 (Bacillus subtilis), IIS15a (Bacillus cereus) y la IIIS10 (Bacillus subtilis); mientras que en general se obtuvieron 12 aislados que resultaron ser muy buenos formadores de biopelículas para ambos tiempos de incubación analizados. Los resultados obtenidos muestran además, una estimulación del crecimiento en micro placa (Crecimiento total, no así en biopelícula) con la adición del suplemento de glucosa.

Por otra parte, los resultados positivos de la prueba de ureasa, nos inducen a pensar que se trata de cepas fuertemente productoras de ureasa y se deberá contar firmemente con ellas al considerar los resultados de bioprecipitacion de carbonatos, además de que una de ellas la cepa IS16 (Bacillus subtilis), tuvo los mejores resultados en cuanto a formación de biopelículas. Todos estos factores, unidos a la buena producción de ureasa nos podrían estar indicando que estamos ante un buen aislado productor de cristales de calcio con estructuras que resultan con buenas características para su utilización en la restauración del patrimonio (esto se corrobora en el cuadro 3, al analizar su alta productividad en calcita).

Los resultados obtenidos sugieren que las cepas [IIIS4 (Bacillus megaterium), IIIS5 (Bacillus simplex), IIIS9b (Bacillus subtilis), 21 (Pantoea agglomerans) y IS5 (Bacillus subtilis)] resultaron ser las mejores en cuanto a bioprecipitación de cristales de carbonato de calcio. En general estas cepas tienen un comportamiento muy similar al mostrado por las cepas [IS16 (Bacillus subtilis), IIS15a (Bacillus cereus) y IIIS10 (Bacillus subtilis)] en cuanto al proceso de formación de cristales, comprobándose con ellas que los resultados obtenidos a los 15 días no difieren a simple vista de los obtenidos a los 22 días.

Es importante mencionar que el $80 \%$ de las cepas probadas en bioprecipitación pertenecen a las biopelículas II y III de los puntos muestreados y que la mayoría de ellos fueron aislados a partir del punto III que corresponde al monumento en el que se observaron visibles signos de deterioro

Los microorganismos obtenidos en este trabajo como potenciales formadores de biopelículas y toda la información recabada, sirve de base para el desarrollo futuro de potenciales aplicaciones que podrían cubrir diferentes campos como: bioprecipitación de cristales de carbonato de calcio para la conservación de monumentos históricos, desarrollo de consorcios para potenciales sistemas de biorremediación y tratamiento de residuales, entre otros potenciales usos. 


\section{REFERENCIAS:}

1. Adolphe, J.M., Loubiere, J.F., Paradas, J y Soleilhavoup, F. 1990. Procede de traitement biologique d'une surface artificielle. European patent 90400G97.0 (after French patent 8903517, 1989).

2. Anne, S., Rozenbaum, O., Andreazza, P y R.Jean-Luis. 2010. Evidence of a bacterial carbonate coating on plaster samples subjected to the calcite bioconcept biomineralization technique. Constr. Build. Mater. 24:1036-1042.

3. Bachmeier, K.L., Williams, A.E., Warmington, J.R y Bang SS. 2002. Urease activity in microbiologically-induced calcite precipitation. J Biotechnol. 93:171-81.

4. Castanier, S., Le Metayer-Levrel, G y Perthuisot, J.-P. 1999. Ca-carbonates precipitation and limestone genesis - the microbiogeologist point of view. Sediment. Geol.126: 9-23.

5. Chaurasia, R.K \& V.V. Verma.2014 Microbial carbonate precipitation by urease producing bacteria in cementitious materials. Intern.J.Adv. Biotech. Res. 15:671-679.

6. Daskalakis, M.I., Rigas, F., Bakolas, A., Magoulas, A., Kotoulas , G., Katsikis, I., Karageorgis, A.P and A. Mavridou. 2015. Vaterite bio-precipitation indiced by Bacillus pumilus isolated from a solutional cave in Paiania, Athens, Greece. Internationationl Biodeterioration \& Biodegradation.99: 7384

7. Decho, A.W.2010. Overview of biopolymer-induced mineralization: What goes on in biofilms? Ecol. Eng.36:137-144.

8. De Muynck,W., Cox, K., De Belie, N y Verstraete,W. 2008a. Bacterial carbonate precipitation as an alternative surface treatment for concrete. Constr. Build. Mater.22:875-885.

9. De Muynck,W., Debrouwer, D., De Belie, N y Verstraete,W. 2008b. Bacterial carbonate precipitation improves the durability of cementitious materials. Cem. Concr. Res.38:1005-1014.

10. De Muynck, W., De Belie, N y Verstraete, W. 2009. Microbial carbonate precipitation in construction materials: a review. Ecol. Eng.36:118-136.

11. De Muynck, W., Verbeken, K., De Belie, N y Verstraete, W. 2010. Influence of urea and calcium dosage on the effectiveness of bacterially induced carbonate precipitation on limestone. Ecol. Eng. 36:99-111.

12. Dick, J., De Windt, W., De Graef, B., Saveyn, H., Van der Meeren, P., De Belie, N y Verstraete, W. 2006. Bio- deposition of a calcium carbonate layer on degraded limestone by Bacillus species. Biodegradation. 17:357-367.

13. Djordjevic, D., Wiedmann, M y McLandsborough. L.A.2002. Microtiter plate assay for assessment of Listeria monosytogenes biofilm formation. Appl.Env.Microbiol.68:2950-2958.

14. Eckardt, F. E. W. 1985. Solubilization, transport and deposition of mineral cations by microorganisms. Efficient rock weathering agents. En: Drever, J. I. (Ed): The Chemistry of Weathering, pp. 161-173.

15. Ercole, C., Cacchio, P and M. Del Gallo. 2014. Microbial biotechnologies to preserve and restore Stone monuments. Microcopy: advances in scientific research and education.

16. Hammes, F y Verstraete, W. 2002. Key roles of $\mathrm{pH}$ and calcium metabolism in microbial carbonate precipitation. Rev. Environ. Sci. Biotechnol.1:3-7.

Nexo Revista Científica Vol. 28, No. 01, pp. 25-40/Junio 2015 
17. Jimenez-Lopez, C., Rodriguez-Navarro, C., Piñar, G., Carrillo-Rosua, F.J., Rodriguez-Gallego, M y Gonzalez-Muñoz, M.T. 2007. Consolidation of degraded ornamental porous limestone stone by calcium carbonate precipitation induced by the microbiota inhabiting the stone. Chemosphere.68:19291936.

18. Jimenez-Lopez, C., Jroundi, F., Pascolini, C., Rodriguez-Navarro, C., Piñar-Larrubia, G., Rodriguez-Gallego, M y Gonzalez-Muñoz, M.T. 2008. Consolidation of quarry calcarenite by calcium carbonate precipitation induced by bacteria activated among the microbiota inhabiting the stone. Int. Biodeterior. Biodegrad.62:352-363.

19. Jroundi, F., Fernadez-Vivas, A., Rodriguez-Navarro, C., Bedmar, EJ y González-Muñoz, M.T.2010. Bioconservation of Deteriorated Monumental Calcarenite Stone and Identification of Bacteria with Carbonatogenic Activity. Microb.Ecol.60:39-54.

20. Kumari, B. 2015. Microbial concrete: A multi-purpose building material- An overview. International Journal of Advances in Engineering \& Technology. Vol.7, $\mathrm{N}^{\circ}$ 6, pp: 1608-1619. ISSN:22311963.

21. Krumbein, W. E. 1988. Microbial interactions with mineral materials. In: Houghton, D., Smith, R., Eggins , H. O. W. (ed.), Biodeterioration 7, pp. 78-100. Elsevier, New York, USA.

22. Laiz, L., Miller, A.Z., Jurado, V., Ekatova, E., Sánchez-Moral, S., González, J.M., Dionisio, A., Macedo, M.F y Saiz-Jimenez, C 2009. Isolation of five Rubrobacter strains from biodeteriorated monuments. Naturwissenschaften.96:71-79.

23. Le Metayer-Levrel, G., Castanier, S., Orial, G., Loubiere, J.F y Perthuisot, J.P.1999. Applications of bacterial carbonatogénesis to the protection and regeneration of limestones in buildings and historic patrimony. Sediment. Geol.126:25-34.

24. Nemati, M y Voordouw, G. 2003. Modification of porous media permeability, using calcium carbonate produced enzymatically in situ. Enzyme Microb Technol.33:635-42.

25. Páramo-Aguilera, L.A; Narváez-Zapata, J y De la Cruz, E. 2011. Aislamiento e identificación en biopelículas provenientes del Castillo Chapultepec, Ciudad de México. Nexo Vol 24, No 02, pp 8391, dic. 2011.

26. Páramo-Aguilera, L.A; Ortega-Morales, B.O and Narváez-Zapata, J.A. 2012. Culturable fungi associated with urban Stone surfaces in Mexico City. Vol.15. Electron. J. Biotechnol. DOI: 10.2225/vol15-issue4-fulltext-6 RESEARCH ARTICLE.

27. Piñar, G., Jimenez-Lopez, C., Sterflinger, K., Ettenauer, J., Jroundi, F., Fernandez-Vivas, A y Gonzalez-Muñoz.M.T 2010. Bacterial community dynamic during the application of a Myxococcus xanthus-inoculated culture medium used for consolidation of ornamental limestone. Microb. Ecol.60:15-28.

28. Quian, C., Luo, L., Ren, R., Wang, R.L., Pan. Q and Chen .H. 2015. Self-healing and repairting concrete cracks based on biomineralization. Key.Eng.Mat. 629-630:494-503.

29. Rivadeneyra, M.A., Parraga, J., Delgado, R., Ramos-Cormenzana, A y Delgado, G. 2004. Biomineralization of carbonates by Halobacillus trueperi in solid and liquidmedia with different salinities. FEMS Microbiol. Ecol.48:39-46.

30. Rodriguez-Navarro, C., Rodriguez-Gallego, M., Ben Chekroun, K y Gonzalez-Munoz, M.T. 2003. Conservation of ornamental stone by Myxococcus Xanthus induced carbonate biomineralization.

Nexo Revista Científica Vol. 28, No. 01, pp. 25-40/Junio 2015 
Appl. Environ. Microbiol.69:2182-2193.

31. Silva-Castro, G.A., Uad, I., González-Martínez, A., Rivadeneyra, A., González-López, A and M.A. Rivadeneyra. 2015. Bioprecipitation of calcium carbonate crystal by bacteria isolated from saline environments grown in culture media amended with seawater and real brine. BioMed research International. Article ID 816102.

32. Talaiekhozen, A., Keyvanfar, A., Andalib, R., AbuMajid,M.Z., Fulazzaky,M.A, Zin, R.M., Lee, C.T., Hussin, M.W., Hamzah, N., Marwar,N.F and H.I. Haidar. 2014. A review of self-concrete research development. J. Environ.Treat. Tech. 2:1-11.

33. Tiano, P., Biagiotti, L y Mastromei, G. 1999. Bacterial bio-mediated calcite precipitation for monumental stones conservation: methods of evaluation. J. Microbiol. Methods. 36:139-145.

34. Verma, R.K., Chaurasia, L., Bisht, V and M. Thakur. 2015. Bio-Mineralization and bacterial carbonate precipitation in Mortar and concrete.

35. Videla, H. A., Guiamet, P. S y Gómez de S. 2003. Biodeterioro de materiales estructurales de sitios arqueológicos de la civilización maya. Revista del Museo de La Plata Publicación Técnica y Didáctica.44:1-11.

36. Warscheid, T., Petersen, K y Krumbein, W. 1988. Effect of cleaning on the distribution of microorganisms on rock surfaces. En: Houghton, D., Smith, R., Eggins, H. O. W. ( eds). Biodeterioration 7, pp. 455-460. Elsevier, New York, USA.

\section{NOTACION}

UFC/mL: Unidades formadoras de colonias por mililitro.

LB: Medio de cultivo Luria Bertani Miller

CaCO3: Carbonato de Calcio

CBG. Centro de Biotecnología Genómica

IPN: Instituto Politécnico Nacional

I, II y III: Puntos muestreados según las biopelículas analizadas.

CICY: Centro de Investigación Científica de Yucatán.

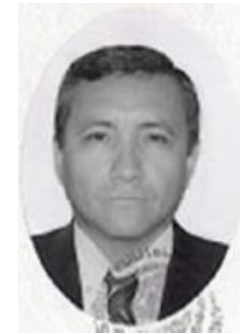

Leandro Páramo Aguilera, Graduado como Ingeniero Químico con maestría en Ingeniería Química y énfasis en procesos biotecnológicos, en el Instituto Superior Politécnico "José Antonio Echeverría", ISPJAE, de la Ciudad de la Habana, Cuba, en el año 1990. En 1997 se gradúa como Master en Microbiología y énfasis en bacteriología en la Universidad de Costa Rica, UCR. Doctorado en Ciencias de la Biotecnología Genómica en el IPN (Instituto Politécnico Nacional) de México en 2012. Amplia experiencia en el desarrollo de procesos biotecnológicos (biofertilizantes, bebidas alcohólicas, fermentados lácteos, bioprospección etc) y asesoría a procesos alimenticios y agrícolas relacionados con biotecnología. 